\title{
Finite Element Analysis of Embankment with Soft Foundation Reinforced by Geogrids
}

\author{
Zhang $\mathrm{Yu}{ }^{1}$, Zhang Jianhui ${ }^{1}$, Zhang $\mathrm{Xu}{ }^{1}$, Pan Xiaodong ${ }^{1}$, Lei Hongwei ${ }^{2}$, Cui Hao ${ }^{2}$ \\ ${ }^{1}$ Institute of civil engineering, Hebei University, Baoding, Hebei, China. \\ 2 Tianchen Engineering Co. Ltd, Hebei Construction Group, Baoding, Hebei, China. \\ Email: zhangyulil@163.com
}

\begin{abstract}
In order to appraise the effect on which geotechnical reinforce soft soil foundation, based on a finite element model of reinforced embankment on soft ground, the stability of soft foundation with step loading during the construction of subgrade was studied, and the influencing factors of reinforced effect were analyzed. The results show that reinforced by geogrid the lateral displacement of the foundation can be controlled effectively with little effect on the vertical displacement; with the increase of the embankment fill, the tension of geogrid is gradually increasing, and its peak is gradually moving to the middle line of subgrade; multi-layers geogrid is better, the effect of 2 layers geogrid is significantly better than 1 layer, the effect of 4 layers is not obvious compared with 2 layers; the closer the reinforcing position is to the ground, the better the effect; with lateral displacement of slope side becoming smaller with increase of the reinforced modulus, the reinforcement effect can be improved.
\end{abstract}

Keywords: Finite element analysis, soft foundation embankment, step loading, geogrid.

\section{Introduction}

With the rapid development of China's economy, capital investment in infrastructure has been increasing, traffic and highway networks are being improved step by step. China is a vast country with complicated geological conditions. Therefore, the road is inevitable to pass through the soft clay regions with poor geological conditions [1].

In recent years, geogrid has been widely used in road construction because of its high tensile strength, tear resistance, good toughness, integrity and creep property[2]. It can effectively improve the construction conditions of subgrade, improve the shear strength of subgrade, reduce the uneven settlement of subgrade, improve the stability of embankment, and control the development of subgrade settlement[3]. But in view of the current situation, due to the lack of appropriate technical standards, there is not enough theoretical basis for the application of Geogrid in the engineering. Design calculation falls far behind production practice. The backward of theoretical research, on the one hand, caused the blind application, induced engineering problems and waste, and on the other hand, limited the further development of the geogrid in strengthening subgrade. Therefore, it is necessary to make a thorough and systematic study on the work effect of geogrid combining with concrete engineering. Qian Jinsong[4] has used ANSYS software to carry out three-dimensional finite element analysis of embankment reinforced by geogrid. Sensitivity analysis of single factor parameters of geogrid modulus was carried out, and its influence on the overall performance of reinforced embankment was verified. Hu Youchang[5] has studied the influence of reinforcement spacing, embankment friction angle, cohesion and other factors on displacement and stress distribution of reinforced embankment by indoor model test and finite element numerical analysis method. Wang Xiequn[6] has analyzed the influence law of geogrid type, filler type and compaction degree on the strength characteristics of geogrid-soil interface by large direct shear test. Most scholars have focused on the analysis of the geogrid characteristics of the built subgrade, and rarely studied the role of geogrid in the process of graded loading.

Combining with the engineering practice, in this paper a finite element model of geogrid reinforcing soft soil subgrade was established by using ANSYS software to study the effect of geogrid reinforcement of soft soil subgrade under the condition of step loading, and some meaningful conclusions are drawn. 


\section{$2 \quad$ Finite Element Model}

\subsection{Soil Constitutive Relation}

The deformation characteristics of soil are complex. The commonly used models are elastic nonlinear model, elastic-plastic model, ideal or rigid plastic model and visco-elastic-plastic model. In this paper, Drucker-Prage model is used to simulate soil nonlinearity, and the yield condition of soil is generalized Mises criterion[7]. The expression is:

$$
F=\sqrt{J_{2}}-k-\alpha I_{1}=0
$$

$\alpha$ and $k$ are the material parameters for the Drucker-Prager model. They can be expressed by soil cohesion $C$ and internal friction angle $\varphi$ :

$$
\begin{gathered}
\alpha=\frac{\sin \phi}{\sqrt{3\left(3+\sin ^{2} \phi\right)}} \\
k=\frac{\sqrt{3} C \cos \phi}{\sqrt{3+\sin ^{2} \phi}}
\end{gathered}
$$

Soil is simulated by 4-node quadrilateral element PLANE42.

\subsection{Constitutive Relation of Geogrid and Reinforced Soil Interface}

The geogrid can only be tensioned, cannot be pressed, and has no bending rigidity. In general, the stress strain of geogrid is within its elastic range, so it is treated as linear elastomer in the analysis process[8-9]. Element Link1, a one-dimensional bar element is used to simulate geogrid.

Because the stiffness changes greatly, the contact element is needed to simulate the nonlinear state at the reinforced soil interface. In the process of numerical analysis, the simulation of contact surface is an important and difficult point. The successful simulation of the contact surface is the key to the simulation results. There are three contact modes in ANSYS: point-point contact, point-surface contact, surface-surface contact, and the contact element used in each contact is applicable to the corresponding problem[10]. Because the geogrid was adopted by the two-dimensional bar element for simulation, the two-dimensional rod element in ANSYS cannot be applied to the point-surface contact and face-surface contact, so the contact element is used to select element Contac12.

\subsection{Establishment of Calculation Model}

In a soft soil region, the width of the embankment is $28 \mathrm{~m}$, the filling height of the embankment is $4 \mathrm{~m}$, the slope is $1: 1.5$, the overall section of the subgrade is $150 \mathrm{~m}$, and the vertical of the foundation is $20 \mathrm{~m}$. Typical sections are shown in figure 1. The geogrid is laid on the sand cushion with a thickness of $1.0 \mathrm{~m}$. There are two layers of soil in foundation, the upper layer is $8 \mathrm{~m}$ thick mucky soil, and the lower layer is $12 \mathrm{~m}$ thick silty clay. The soil parameters of embankment and soft soil foundation are shown in Table 1. The tensile strength of geogrid is $2000 \mathrm{KN} / \mathrm{m}$.

According to the actual condition of the construction of the embankment, the filling is divided into four stages, each of which is a condition. Condition 1 filling height is $1.5 \mathrm{~m}$, condition 2 filling height is $2.0 \mathrm{~m}$, condition 3 filling height is $0.3 \mathrm{~m}$, condition 4 filling height is $0.2 \mathrm{~m}$. It is assumed that soil consolidation is not considered. The total stress method is used for calculation and analysis. Modeling analysis is carried out according to plane strain problem, and the mesh of finite elements is shown in figure 2 .

Table 1. Calculation parameter

\begin{tabular}{lcccccc}
\hline \multicolumn{1}{c}{ Soil } & $\gamma\left(\mathrm{KN} / \mathrm{m}^{3}\right)$ & $\mathrm{v}$ & $\mathrm{E}(\mathrm{MPa})$ & $\mathrm{C}(\mathrm{kPa})$ & \multicolumn{1}{c}{$\phi$} & Dilation Angle \\
\hline Embankment fill & 19.3 & 0.27 & 35 & 25 & 32 & 0 \\
Sand cushion & 22.8 & 0.23 & 52 & - & 39 & 0 \\
Mucky soil & 17.5 & 0.38 & 4 & 8 & 6 & 0 \\
Silty clay & 18.1 & 0.28 & 11 & 18 & 24 & 0 \\
\hline
\end{tabular}




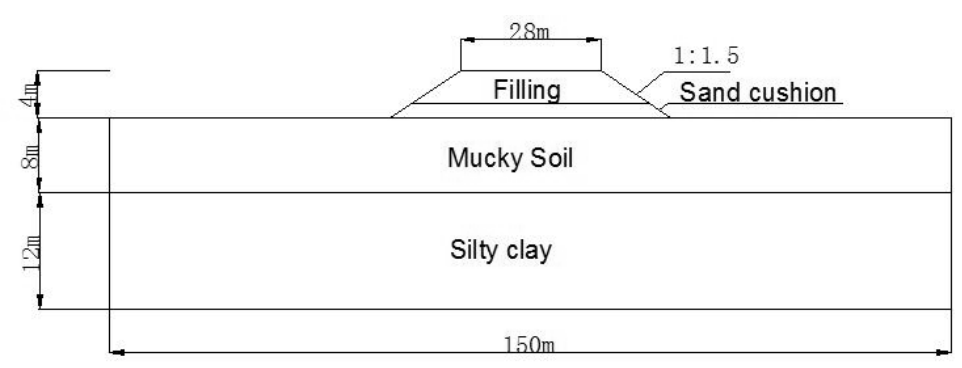

Figure 1. Calculation model section

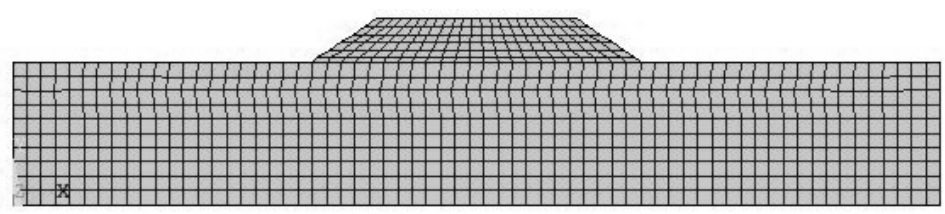

Figure 2. Mesh generation

\section{$3 \quad$ Result and Analysis}

\subsection{Internal Force Analysis of Geogrid}

Fig. 3 is the internal force distribution curve of geogrid under different working conditions. As shown in Figure 3, when the load is small, that is, when the working condition is 1, the tension of the geogrid varies little. With the increase of embankment fill, the tensile force of geogrid increases gradually, and the peak value gradually moves to the middle of subgrade. Along the midline of subgrade to the direction of shoulder, the tension of geogrid increases first and then decreases. Except for condition 1, the tensile force of geogrid increases slowly before the center line of subgrade is $4 \mathrm{~m}$, and increases rapidly after $4 \mathrm{~m}$. The maximum value appears at $12 \mathrm{~m}$ near the center line of subgrade, which is consistent with the results of $\mathrm{Wu}$ Jinghai's research[11].

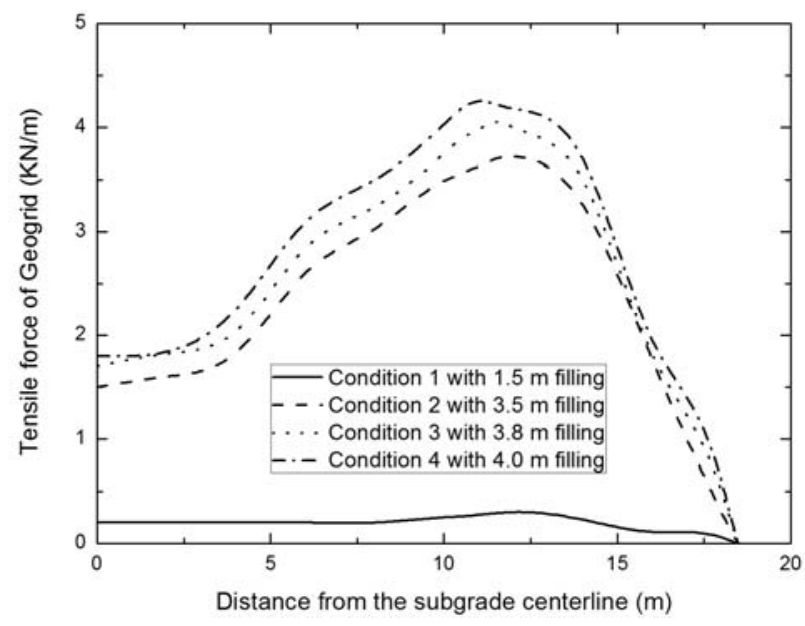

Figure 3. Internal force distribution curve of geogrid

\subsection{Vertical Displacement}

Fig. 4 is the vertical displacement of the ground when the embankment is loaded and the geogrid is laid or not on the conditions 1 and 4. As can be seen from Figure 4, with the increase of the earth fill, the vertical displacement becomes larger, the maximum vertical displacement appears below the subgrade midline, and the overall vertical displacement of the subgrade decreases gradually along the shoulder 
direction. In condition 1, no matter whether to lay geogrid or not, the maximum vertical displacement is almost unchanged. In condition 4, the maximum vertical displacement of laying geogrid is lower than the maximum vertical displacement when unpaved, but the effect is not obvious. Therefore, the geogrid cannot effectively reduce the vertical displacement of the subgrade. The bending strength of geogrid is not taken into account, so the vertical displacement is not affected. However, due to the local tensile force of geogrid, the stress field of soft foundation changes and the integrity of structure is strengthened, so the vertical displacement has a decrease[12].

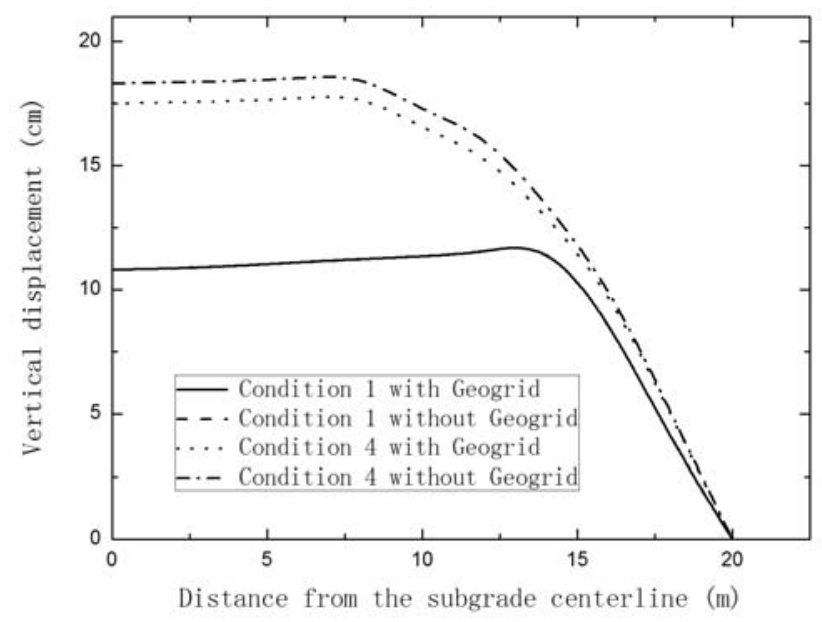

Figure 4. Vertical displacement at the top of soft soil

\subsection{Lateral Displacement}

Fig. 5 is the lateral displacement at the toe of slope when the geogrid is laid or not on the conditions 1 and 4. From Figure 5, it can be seen that the lateral displacement of soft soil increases with the increase of embankment fill. In condition 4, the maximum lateral displacement of the slope is decreased by $12.90 \%$ compared with unpaved geogrid. It is shown that the lateral displacement of the foundation can be effectively reduced by the reinforcement, which is consistent with the results of Yang Xiaohua's research[13]. When the geogrid is not laid, the maximum lateral displacement appears at $1.0 \mathrm{~m}$ away from the ground. After laying geogrid, the maximum lateral displacement appears in the range of $1.0 \sim 1.5 \mathrm{~m}$ away from the ground. This shows that the maximum lateral displacement of soft soil foundation is gradually developed to the depth after laying geogrid, which is beneficial to the stability of soft soil foundation.

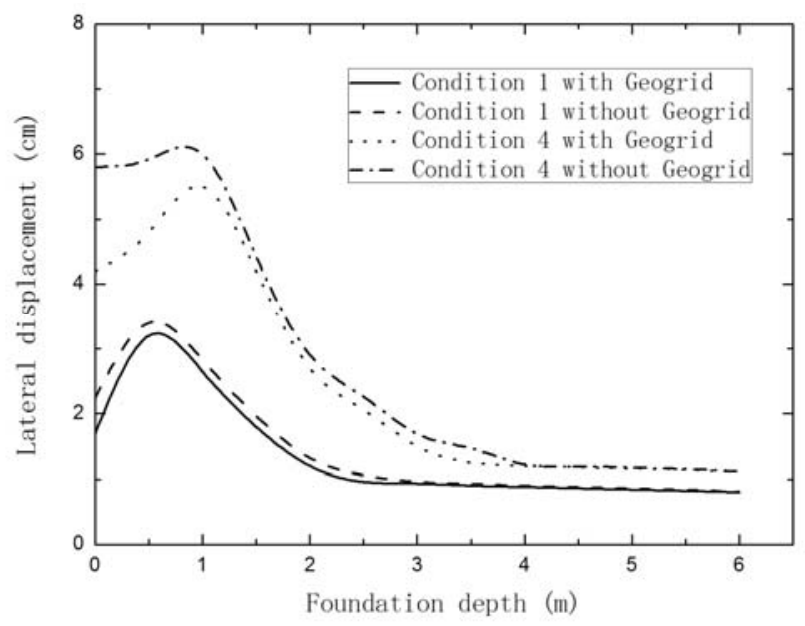

Figure 5. Lateral Displacement at the foot of Slope 


\section{Sensitivity Analysis of Other Parameters}

\subsection{Effect of the Number of Geogrids on Reinforcement Effect}

Based on the finite element model, 3 kinds of reinforcement methods are analyzed: 1 layer of reinforcement, 2 layers of reinforcement and 4 layers of reinforcement. The first layer is laid between the ground floor and the sand cushion, and the second layer is laid at $1 \mathrm{~m}$ away from the ground, and the third layer is laid at $3.5 \mathrm{~m}$ from the ground, and the fourth layer is laid at $3.8 \mathrm{~m}$. As can be seen from Figure 6, different reinforcement layers have some influence on the reinforcement effect. Compared with the unreinforced, the maximum lateral displacement of slope angle with the reinforced 1 layer, the reinforced 2 layers and the reinforced 4 layers are decreased by $14.52 \%, 16.13 \%$ and $16.45 \%$ respectively. It is better to lay geogrid between the original ground and sand cushion than at $1 \mathrm{~m}$ above ground, and reinforced the closer to the original ground, the better the effect. Laying 2 layers of geogrid is better than laying 1 layer. Laying 4 layers of geogrid, compared with the 2 layers, shows better effect, but not significant. Therefore, the closer the reinforcing position is to the ground, the better the effect. If the multi-layer reinforcement is selected, the "top sparse, bottom dense" approach should be used as far as possible.

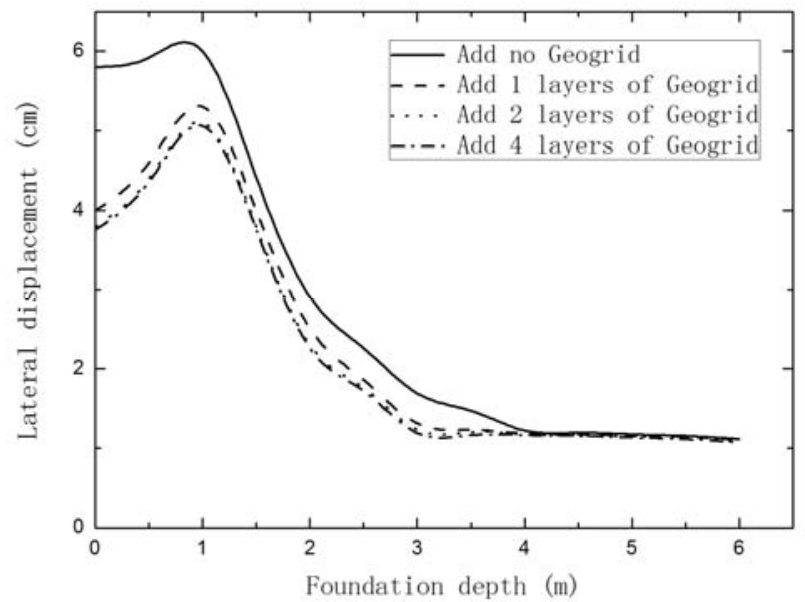

Figure 6. Lateral displacement at the foot of slope with different reinforcement numbers

\subsection{Effect of the Modulus of Geogrid on Reinforcement Effect}

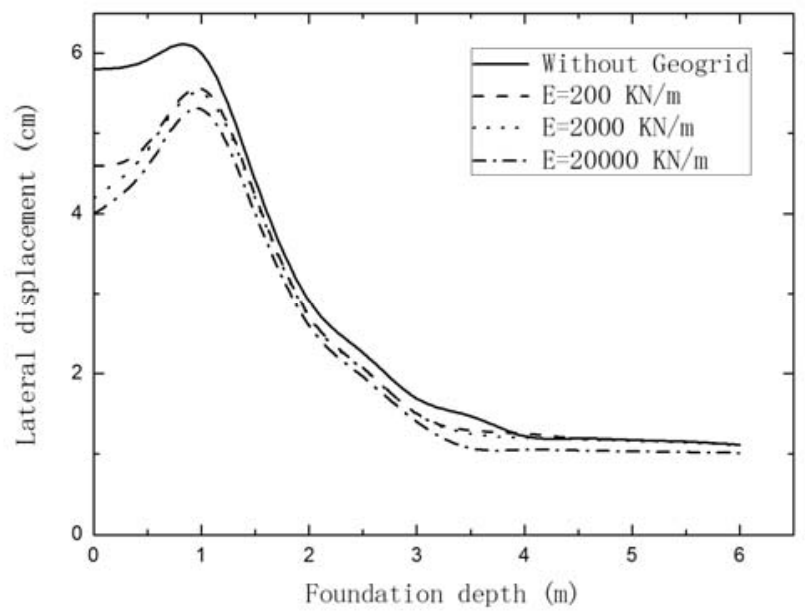

Figure 7. Lateral displacement at the foot of slope with different reinforcement modulus 
The modulus of geogrid in the finite element calculation model is changed to $200 \mathrm{KN} / \mathrm{m}, 2000 \mathrm{KN} / \mathrm{m}$ and $20000 \mathrm{KN} / \mathrm{m}$ respectively, comparing with the case of no reinforcement. Figure 7 shows the lateral displacement in the foot of the embankment with different reinforcement modulus. It can be seen from the figure that the lateral displacement of the points at the slope angle decreases gradually with the increase of the modulus of reinforcement, which is consistent with Qian Jinsong's research[4]. But it is not economical to increase the reinforcement effect by increasing the modulus of reinforcement, and the modulus of reinforcement is too low, which will make the reinforcement effect unsatisfactory. Therefore, in the actual project, it is necessary to consider the reasonable reinforcement modulus range of geogrid.

\section{Conclusion}

(1) The reinforced material added into soil can effectively reduce the lateral displacement of the foundation, but it has little effect on reducing the vertical displacement of the subgrade. With the increase of embankment fill, the tensile force of geogrid increases gradually, and the peak value gradually moves to the middle of subgrade.

(2) Multi-layers geogrid is better, the effect of 2 layers geogrid is significantly better than 1 layer, the effect of 4 layers is not obvious compared with 2 layers. The reinforcing position is different, and the effect is different. The closer the reinforcement position is to the ground, the better the effect.

(3) Increasing the modulus of reinforcement can decrease the lateral displacement of slope angle and improve the reinforcing effect.

\section{References}

1. S.L. Ye, "Application Manual of foundation treatment engineering," Beijing: China Construction Industry Press, 1998.

2. C.C, Gu, Q.G.Yang, Z. Zhang, "Numerical analysis of embankment on soft clay foundation reinforced by geogrids," Journal of Hohai University (Natural Science Edition), 2005, (06): 75-79.

3. Chen Jianfeng, Li Huili. Status and Prospect of Research on Geosynthetics Soil Interface Properties. Chinese Journal of Underground Space and Engineering, 2009, 5 (05): 1049-1054.

4. J.S. Qian, J.M. Ling, and Q.L. Huang, "3D Finite Element Analysis of Embankment Reinforced by Geogrid," Journal of Tongji University (Natural Science Edition), 2003, (12): 1421-1425.

5. Y.C. Hu, Y.M. Zhang, H.Q. Lin, Y.S. Cai and H.G. Guo, "Research on Effecting Factors of Embankment Reinforced with Geogrid," Journal of Wuhan University of Technology (Traffic science and Engineering Edition), 2008, (02) : 206-209.

6. X.Q. Wang, J.F. Zhang, L. Zou, J.H. Wen and C. Liu, "A shear strength model of geogrid-soil interface and its influence factors," Journal of Civil Engineering, 2013,46 (04): 133-141.

7. Y.H. Wang and B.T. Wang, "Calculation of Subgrade Settlement Reliability based on ANSYS," Subgrade Engineering, 2008, (01): 65-66.

8. W.W. Liu, Y.H. Li and B.Y. Zhang, "The Numerical Analysis on Reinforced Characteristic of Geogrids in Roadbed Widening Engineering," Highway Engineering, 2016, 41 (03): 158-161.

9. R.F. Wang and J.H. Pi, "Comparative Analysis of Improving Soft Soil Foundation with Combining Geogrids and Gravel Piles," Journal of Wuhan University (Engineering Science), 2011, 44 (01): 86-89.

10. J.Q. Jiang and Y.S. Zou, "Numerical Simulation of Reinforced Retaining Wall under Dynamic Loads," Journal of Hunan City University (Natural Science Edition), 2006, (04): 12-14.

11. J.H. Wu, "Experimental Study and F E Analysis of Geosynthetic Reinforcement," Tianjin: Tianjin University, 2002.

12. H.Y. Jiang. "The Finite Element Analysis of Embankment on Soft Grounds Reinforced by Geogrids," Northeast Forestry University, 2007.

13. X.H. Yang, T.D. Dai and X.Z. Xu, "Geocell Application in Reinforcing Soft Subgrade of Railway," Journal of Traffic and Transportation Engineering, 2005, 5(2): 42-46. 